\title{
Retraction Note to: Generation of topological chaos in the stokes flow in a rectangular cavity
}

\author{
V. V. Meleshko • O. B. Kurylko • A. A. Gourjii
}

(C) Springer Science+Business Media New York 2014

Retraction to: Journal of Mathematical Science 2012, 185(6):858-871

DOI 10.1007/s10958-012-0968-z

The article has been retracted by the author A. A. Gourjii. It has been found to contain substantial material that was already published in M.A. Stremler and J. Chen (2007) Generating topological chaos in lid-driven cavity flow, Physics of Fluids 19, 103602 (http://dx.doi.org/10.1063/1.2772881) as well as from a Virginia Tech doctoral dissertation: J. Chen (2008) Topological chaos and mixing in lid-driven cavities and rectangular channels, Ph.D. Thesis, Virginia Tech, 203 pp. (available at http://scholar.lib.vt.edu/theses/available/etd12012008-120110/unrestricted/dissertation.pdf).

The online version of the original article can be found at http:/ dx.doi.org/10.1007/s10958-012-0968-z.

V. V. Meleshko $(\bowtie) \cdot$ O. B. Kurylko

Shevchenko Kyiv National University, Kyiv, Ukraine

e-mail: meleshko@univ.kiev.ua

\section{A. A. Gourjii}

"KPI" National Technical University of Ukraine, Kyiv, Ukraine 